\title{
Ada Lovelace: First Computer Programmer and Hacker?
}

\section{Dr. Erica Haugtvedt, South Dakota School of Mines \& Technology}

Dr. Erica Haugtvedt is an assistant professor of English and Humanities at South Dakota School of Mines and Technology. She received her Ph.D. in British nineteenth-century literature from Ohio State University in 2015. Erica Haugtvedt works on Victorian popular fiction, transfictionality, seriality, and media history. Her publications include "The Victorian Serial Novel and Transfictional Character" (Victorian Studies (59.3: 2017)), "The Ethics of True Crime: Fictionality in Serial Season One" in The Serial Podcast and Storytelling in the Digital Age (Routledge, 2016), "Sweeney Todd as Victorian Transmedial Storyworld" and "The Sympathy of Suspense: Gaskell and Braddon's Slow and Fast Sensation Fiction in Family Magazines" (both in Victorian Periodicals Review (49.1: 2016, 49.3: 2016)). Her current book project examines the dynamics of transfictional characters in the British long nineteenth century.

\section{Dr. Duane Lewis Abata, South Dakota School of Mines and Technology}

Dr. Abata has worked in academia for over forty years at universities and with the Federal government around the country. He began his career at the University of Wisconsin, served as Associate Dean and Dean at Michigan Technological University and then at the National Science Foundation in Washington, D.C. as program manager in the Engineering Directorate. From 2003 to 2004, Dr. Abata was President of the American Society for Engineering Education. Following his appointment at NSF he served as Dean of Engineering and Engineering Technology at Northern Arizona University and Dean of Engineering at South Dakota School of Mines and Technology. Dr. Abata is currently a tenured full professor in mechanical engineering at South Dakota School of Mines and Technology. His research work focuses in the areas of energy storage and combustion. 


\title{
Ada Lovelace: First Computer Programmer and Hacker?
}

\author{
Erica Haugtvedt and Duane Abata \\ South Dakota School of Mines \& Technology \\ Rapid City, SD
}

\begin{abstract}
Long before today's pervasive digital computers, the first computer programmer and computer hacker was arguably Augusta Ada King, Countess of Lovelace (born in 1815 as Augusta Ada Byron, daughter of the famous poet Lord Byron). She captured the essence of Charles Babbage's Analytical Engine, which was conceptualized by Babbage but was not constructed in his lifetime. An exceptional mathematician, in 1843 she wrote an algorithm to accompany Babbage's Engine and hence is an important role model for women in Science and Engineering. Her contribution to calculate Bernoulli numbers with the Analytical Engine has since been successfully translated, with minor changes, to the $\mathrm{C}$ programming language. As a Victorian computer programmer, it is crucial to remember that she achieved her insights through translating between languages, people, disciplines, and between the imaginary and the real. In doing so, Lovelace was a woman of her time, demonstrating that the intersections of her socioeconomic and gender identity allowed her to be successful despite the dominant patriarchal scientific culture in which she worked. She is thus a valuable historical example for women today, showing that women have long made valuable contributions to STEM. This paper discusses how she accomplished this somewhat hidden achievement and suggests a video and discussion activity geared toward prompting undergraduates to reframe their origin stories for computer science to include women. In another paper, we discuss the details of her algorithm and present a working program for use as an assignment for students in beginning computer classes.
\end{abstract}

\section{Introduction}

In our engineering curriculum, we need to emphasize the human aspects of science and engineering. This need is clearly recognized by our accreditation agency, ABET, which requires a portion of the curriculum to be set aside for such exposure. In order to be creative leaders in Science and Engineering, students need role models who have set an extraordinary precedent. Furthermore, despite recruitment efforts, women remain a minority in engineering fields in the U.S [1]. Psychologist Penelope Lockwood's studies suggest that because "women face negative stereotypes regarding their competence in the workplace, they may derive particular benefit from the example of an outstanding woman who illustrates the possibility of overcoming gender barriers to achieve success" [2]. In this paper, we suggest that using Ada Lovelace as an historical role model in engineering curriculum can help female engineering and science students revise dominant origin narratives surrounding science and engineering disciplines. Bringing history to engineering also allows students to recognize the development of technology as evolutionary. It allows them to understand the role of creativity in the development of engineering and technology and to make interdisciplinary connections between their work and the world. 
It has been argued that the first computer programmer, well before the introduction of the digital mainframe and later the personal computer, was Augusta Ada King, Countess of Lovelace. With an exceptional background in mathematics for a woman of the time, Lovelace wrote the first algorithm and program in 1843. She captured the essence of Charles Babbage's Analytical Engine, which was conceptualized by Babbage but never constructed as a working instrument until 1991 at the $200^{\text {th }}$ anniversary of Babbage's engine by craftsmen at the Computer History Museum in Mountain View, California [3]. Lovelace is an important pioneer for women in Science and Engineering. Her contribution to calculate Bernoulli numbers with the Analytical Engine has since been successfully translated, with minor changes, to the $\mathrm{C}++$ programming language. Her contribution was the result of a sequence of serendipitous events that allowed computer technology to evolve before the advent of the digital computer: most notably, Charles Babbage first conceived of the Difference Engine, which then evolved into the Analytical Engine, which could be programmed with punched cards similar to the successful existing technology of the automated Jacquard Loom. Lovelace's contribution would have been lost to time had it not been for Babbage's presentation of his analytical engine to an audience of aristocratic scientists and politicians in Italy, and Lovelace's fortuitous subsequent translation of Luigi Menabrea's notes from this presentation from French to English.

As a Victorian computer programmer, it is crucial to remember that she achieved her insights through translating between languages, people, disciplines, and between the imaginary and the real. In doing so, Lovelace was a woman of her time, adhering to behavior that was expected of her as an aristocratic Lady. This paper discusses how she accomplished this somewhat hidden achievement. In another paper we discuss the details of her algorithm and present a working program for use as an assignment for students in beginning computer classes.

\section{Ada Lovelace: A Short Biography}

Ada Lovelace was the only legitimate daughter of George Gordon Lord Byron, the famous poet, peer, and politician [4]. Lord Byron achieved an immense reputation for his poetry and playboy antics in his own lifetime and is still regarded as one of the most important British Romantic poets. Shortly after Ada's birth, Lord Byron separated from his wife [4]. He died tragically of disease while fighting in the Greek War of Independence in 1824, when Ada was eight years old [4]. In 1833, the novelist Edward Bulwer Lytton wrote of Byron's death: "When Byron passed away, we turned to the actual and practical career of life: we awoke from the morbid, the dreaming, the 'moonlight and dimness of the mind,' and by a natural reaction addressed ourselves to the active and daily objects which lay before us" [5]. Bulwer-Lytton's observation elucidates the received contrast between the dreamily Romantic and dutifully practical Victorian ages. Lovelace was the daughter of a Romantic, who grew to adulthood in the Victorian era. Her work likewise translates between these supposedly contrasting time periods.

The estrangement between Lovelace's parents was bitter, and Lovelace's mother, herself considered a youthful prodigy in mathematics, committed herself to educating Lovelace in mathematics and science as an antidote against Byron's poetic influence [6]. Lovelace, however, remained attached to the legacy of her father and would not only name her two sons Byron and Gordon, but would request that she be buried next to her father upon her death [6]. Lovelace rejected her mother's opposition between mathematics and poetry. In her thirties, Lovelace wrote 
to her mother that if she couldn't have poetry, could not she at least have a "poetical science" [7]. Lovelace's experience of mathematics was laden with metaphor and intuition. She valued metaphysics equally to mathematics, seeing both as ways of exploring the "the unseen worlds around us" [8]. Lovelace's insight into the potentialities of mathematics beyond strict utility allowed her to translate Babbage's computational algorithms into a vision of programming that anticipated what computing would become for the world.

Lovelace's mathematical abilities began to manifest when she was 17 years old, and her interest in mathematics would dominate her adult life [9]. Lovelace's tutor, Augustus De Morgan, suggested that Ada's skill could lead her to become a "first rate eminence" [7-8]. On 8 July 1835, she married William, 8th Baron King, becoming Lady King [10]. They had three children. Lovelace was a descendant of the extinct Barons Lovelace and in 1838, her husband was made Earl of Lovelace and Viscount Ockham [11], meaning Lovelace became the Countess of Lovelace [12]. In 1834, Lovelace had met Charles Babbage at a dinner party where she heard his ideas for a calculating machine. She was inspired by the "universality of his ideas," which, as her biographer Betty Toole quips, hardly anyone else was [7].

Charles Babbage (1791-1871) was an accomplished scientist, but he never described his groundbreaking Analytical Engine thoroughly in publications meant to be consumed by the public. Born into wealth, Babbage was a regular in London Society and was educated in Mathematics at Cambridge [13]. During the early nineteenth century, Britain was the first nation in the world undergoing industrialization from a largely agrarian economy to one based on trade and manufacturing [5]. Consequently, this period of imperial expansion necessitated mathematical tables that were central to navigation, science, and engineering. These tables were laboriously developed by hand using complicated mathematical functions, and mistakes were known to occur in transcription as well as in calculation [14]. Babbage envisioned the use of mechanization to reduce the fallibility of this process. See Figure 1 and Figure 2 below for images of Ada Lovelace and Charles Babbage, respectively. 


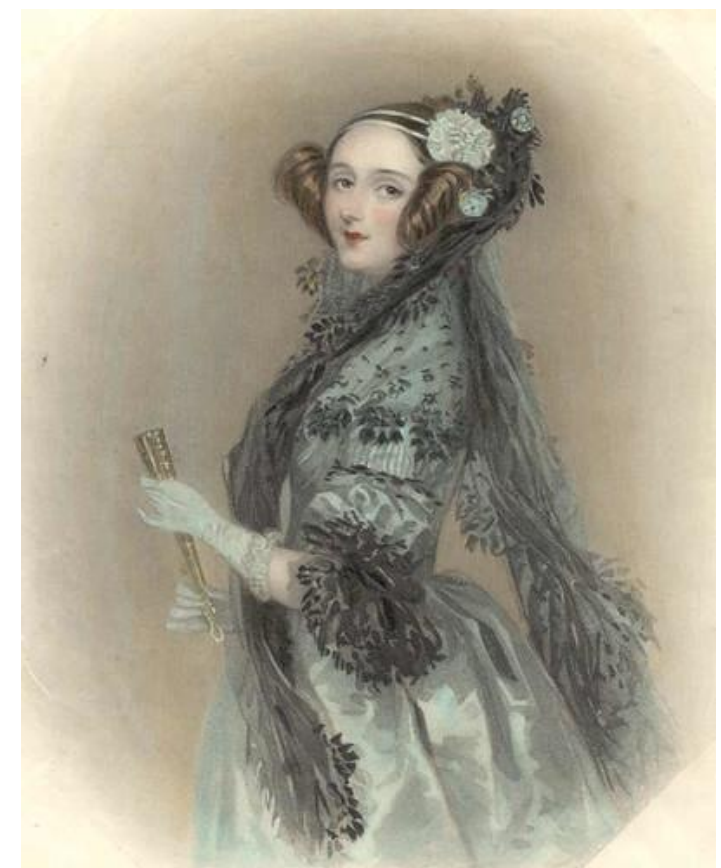

Figure 1., "Ada Lovelace, 1838" by Nefi is licensed under CC BY-NC-SA 2.0

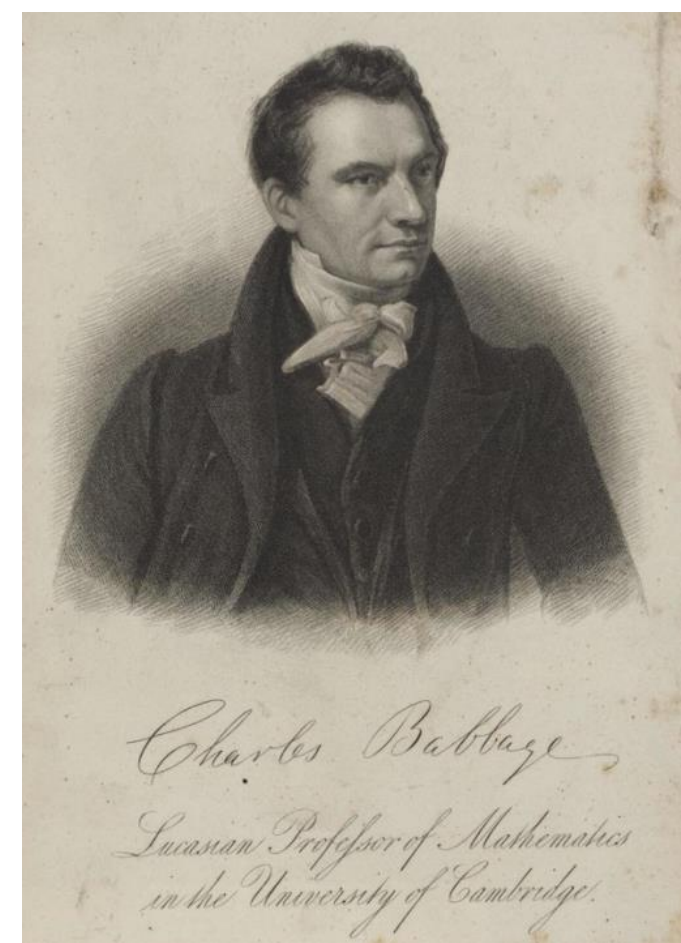

Figure 2., Engraving of Charles Babbage dated 1833, public domain

\section{The Difference Engine and the Analytical Engine}

Previously, Babbage had conceptualized and directed, with substantial financial support from the British government, the partial construction of his first design for a mechanical computer, 
referred to as the 'Difference Engine,' that could perform relatively simple mathematical tasks repeatedly without error [15]. In 1821, Babbage began to design his Difference Engine, a fully mechanical machine to compute values of polynomial functions [16]. Addition and subtraction would be used, and multiplication and division avoided, by using the method of finite differences, thus calculations could be achieved through the use of gears, cogs, and levers [17]. Even though the mathematical design was relatively simple, the invention was made complex by the sheer number of repetitive parts. Even though Babbage had secured government funding for the project, the Difference Engine was never fully produced in the nineteenth century due to cost and manufacturing difficulties. ${ }^{1}$ Work halted in 1832, and government funding was axed in 1842 [16]. However, a small working model was produced in 1822 [16]. He later conceptualized the improved 'Analytical Engine' to perform mathematical tasks but with programmable capabilities from the 1830 s through to his death in 1871.

The Analytical Engine of the 1830s was never actually constructed. Babbage envisioned for the Analytical Engine the use of interchangeable punch cards, much like those used for complex brocade weaving in the 1804 Jacquard Loom, to control the calculator. The Analytical Engine could theoretically thus be "programmed," although it is doubtful that Babbage thought of it in the way that programming is used in today's context. Babbage planned for a loop (or sequence) of Jacquard's punched cards to control the function of the mechanical calculator, which could then use the results of preceding computations [19-20]. In addition to loop control, Babbage also foresaw sequential control and branching (or decision making). Arguably, Babbage's Analytical Engine represents the transition from mechanized arithmetic (addition, subtraction, multiplication, and division) to fully-fledged general-purpose computation (loop, sequential control, and branching) of today, although as the Computer History Museum notes, there is no continual line of development from Babbage's engines to the computers of today [15]. This invention of a punch-card programmable Analytical Engine constitutes Babbage's claim to be a computer pioneer [18].

Notably, Babbage's inspiration, the Jacquard Loom, had been used to weave silk brocade in Lyons, France for decades. Lovelace herself had been impressed by automated looms when she toured the British Industrial midlands with her mother; she wrote in a letter dated September 1, 1834, "This Machinery reminds me of Babbage and his gem of all mechanism" [6]. Babbage himself would make the connection between the Analytical Engine and the Jacquard Loom in his notes on June 30, 1836 [21]. A key element of Babbage's innovation was borrowed from an entirely different purpose and context. See Figure 3, below, for an example of woven fabric made possible by the use of Jacquard head adapted to a dobby loom.

\footnotetext{
${ }^{1}$ Some parts of the Difference Engine prototype from the nineteenth century survive in the Museum of the History of Science, Oxford [30]. In 1991, a functioning Difference Engine was constructed from Babbage's original plans. Built to tolerances achievable in the nineteenth century, the success of the finished engine indicated that Babbage's machine would have worked. His design was finally constructed in 1989-1991, using his plans and nineteenthcentury manufacturing tolerances. It performed its first calculation at the Science Museum, London, returning results to 31 digits. A second Difference Engine, also constructed by the Science Museum, is owned by the technology multimillionaire Nathan Myhrvold and is on display at the Computer History Museum in Mountain View, California [31-33]. There are some differences between the two engines: Myhrvold's engine is the first design by Babbage, and the Science Museum's engine is one of Babbage's later designs.
} 


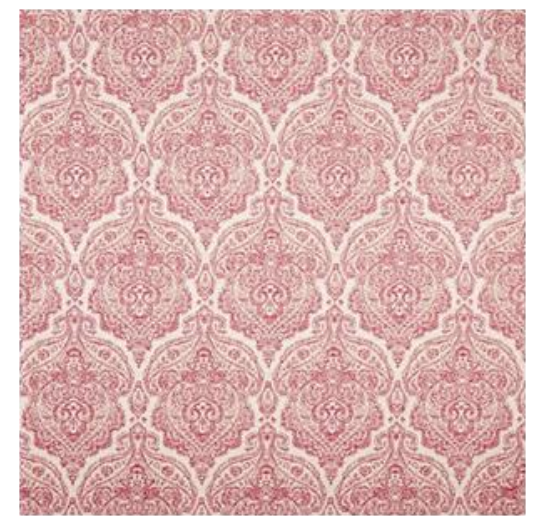

Figure 3. Woven pattern in fabric made possible by the use of a "Jacquard head" adapted to a dobby loom.

Operation of the Jacquard Loom is best observed rather than described. It involves a series of control rods that encounter a flat plate called the "Jacquard head" during the looming process. The Jacquard head has punched holes that either allow or block the rods as they move in and out during the loom stroke. Each rod, if allowed to pass through the Jacquard head, acts upon a small hook on the end that grasps a thread of different colored fabric and the weave is completed with a shuttle. The Jacquard head is mechanically changed every weave row, thus the Jacquard head along with the array of punched cards provide intricate pre-programmed patterns of different thread in the woven fabric [22]. Interestingly, the Jacquard head was conceptualized around 1843 while treadle looms were commonplace, but the head was not adopted for roughly 40 years when dobby looms, or large floor looms used in the mass production of woven fabric, were placed in use. Because of the usefulness, the "Jacquard head" was built to adapt to many different dobby looms, essentially revolutionizing the weaving industry [21-24].

\section{Translation and Metaphor as an Avenue to Discovery}

Babbage was deeply influenced by Jacquard's invention. Replaceable punched cards used to control a sequence of operations is considered an important step in the history of computing hardware although it is important to understand that the punched cards used in Jacquard's loom modification were really not punched cards as we know them today but rather metal plates with carefully drilled holes which were stacked and changed as the weave patterns changed during the weave process. The ability to change the pattern of a loom's weave could be extended to the ability to change the movement of cogs and gears in the operation of a mechanical calculator, allowing it to be programmed for specific operations. ${ }^{2}$ The birth of Babbage's general-purpose

\footnotetext{
2 This punched card concept was later extended by Herman Hollerith in the late 19th century who created a punched card tabulating machine which he used to input data for the 1890 U.S. Census. A large data processing industry using punched-card technology was developed in the first half of the twentieth century - dominated initially by the International Business Machine Corporation (IBM), with its line of unit record equipment. The cards were used for
} 
programmable computer, then, was inspired by translating between seemingly disparate domains. Babbage borrowed from the weaving industry, an industry that literally makes its cloth by pulling threads together. Lovelace had noticed the connection earlier, and understood its significance deeply: she wrote in Notes on "Sketch of the Analytical Engine," "We may say most aptly that the Analytical Engine weaves algebraical patterns just as the Jacquard Loom weaves flowers and leaves" [25]. Invention was importantly achieved through analogy and translation.

Lovelace's own contribution to computer history is itself literally borne of translation. Luigi F. Menabrea, an Italian aristocrat and military engineer, had taken notes on the way that Babbage's Analytical Engine worked based on Babbage's lectures in Turin, Italy. In 1842, Menabrea wrote an article in French, "Sketch of the Analytical Engine Invented by Charles Babbage," explaining the workings of the machine, but being in French, the article was inaccessible to the English public. From 1842-1843, Lovelace translated Menabrea's work from French to English, and in doing so added, at Babbage's personal encouragement, copious notes of her own original thinking that exceeded the article itself by three times its length [7]. Lovelace completed this translation and the original work contained in her notes as a mother of three children under eight years old [7]. These notes contain what many consider to be the first complex computer program - that is, an algorithm designed to be carried out by a machine. Her "prescient comments" included predictions that such a machine as the Analytical Engine might be used to "compose complex music, to produce graphics, and would be used for both practical and scientific use" [7]. Lovelace conjectured a workable program for the entirely hypothetical machine.

Lovelace immediately saw that the applications of the Analytical Engine went beyond mere calculation. She wrote, "the engine might compose elaborate and scientific pieces of music of any degree of complexity or extent" [25]. Furthermore, she saw that the operations could have symbolic results rather than merely numerical: "by means of a few simple provisions, and additions in arranging the mechanism, to bring out a double set of results, viz.- 1 st, the numerical magnitudes which are the results of operations performed on numerical data. . . . 2ndly, the symbolical results to be attached to those numerical results" [24]. In Note G, Lovelace gives proof to her claims by writing a program for calculating the eighth Bernoulli number, which, as computer historian and programmer Sinclair Target discovered, contains a bug in the transposition of two variables in the fourth operation [26]. This may have been a type-setting error. Despite this error, Target calls Lovelace the "first programmer to deserve the title" [26]. Unlike Babbage and Menabrea, who had both written simple programs for the Analytical Engine before Lovelace, Lovelace's program contains both branching and looping, fundamental operations to modern computing [26]. Lovelace's contribution, then, is not merely derivative or replicative of Babbage and Menabrea's prior work but rather demonstrates her deep comprehension of the entity that had been envisioned and extends the ideas they presented. More than the men before her, Lovelace saw the far-reaching implications of computing. Indeed, she was able to achieve her insight because of working between and through disparate languages, worlds, values, and disciplines. She translated between domains.

data entry rather than programming. However, the 1944 IBM Automatic Sequence Controlled Calculator received program instructions from a paper tape punched with holes, similar to Jacquard's string of cards. Later computers executed programs from higher-speed memory, though cards were commonly used to load the programs into memory. Punched cards remained in use in computing up until the mid 1980s. [21] 


\section{Lovelace's Historical Context and Feminist Legacy}

Lovelace's achievement has been increasingly recognized since approximately 2009, when Suw Charman-Anderson launched "Ada Lovelace Day" to encourage people to recognize women pioneers in science and technology [27]. Charman-Anderson chose Lovelace as the figurehead of this movement to rewrite the story of STEM to include great women. Lovelace thus has been celebrated increasingly in recent years as the foremother of computer programming. In these laudatory paeans, she is often introduced as a woman ahead of her time. Indeed, this in line with Beddoes and Berrogo's content analysis of engineering education articles from 1995-2008, in which they find that "the tendency of prior research has been to "cast women in a deficit role, aggregating them into one category, and viewing them as 'other"' [1 qtd. Godfrey, 2003]. The feminist theories most often engaged in Engineering Education have been liberal feminism or standpoint feminism, both of which risk universalizing women's experience and implying that the "problem" is with women and not engineering culture [1]. "Exceptional" women can break through in the culture, but feminine-conforming women are implied to not belong. Initiatives that focus on recruiting and retaining women into a masculinist culture without addressing the biases and limitations of that culture risk only perpetuating the problems. Beddoes and Berrego recommend integrating intersectional and masculinity studies approaches to feminism to engineering education theory in order to better understand the ways that gender is constructed and experienced within the culture of engineering and engineering education. Below, we show that the intersections of Lovelace's identity, along with her historical context, allowed her to achieve her breakthroughs, therefore rewriting a male-dominated history of science and allowing women to see themselves in origin narratives of their discipline. Ada Lovelace could not have invented complex computer programming if she hadn't been born into the British nineteenth century. Instead of being a woman ahead of her time, we propose instead that Lovelace's achievements were because she was very much a woman of her time.

The nineteenth century is often represented as an era oppressive to women, in which the ideology of the "Angel in the House," - encouraging upper-class women to be tender, innocent, spiritual and, in various degrees, submissive-dominated [5]. But the status of women in the Victorian era was not nearly so simple, and a figure such as Ada Lovelace highlights the ways in which her gender and socio-economic class both oppressed and privileged her during her lifetime.

The Woman Question, as the Victorians dubbed the various issues relevant to women at the time, highlights that "proper" gendered behavior was under intense debate. Gender cannot be separated from socio-economic class during this period: while the copious leisure of Victorian ladies was a status symbol for the upper classes, during the mid-Victorian period, one-quarter of England's female population held jobs, most onerous and low-paying [5]. Lower-class women worked hard and constantly, inside and outside the home. Meanwhile, upper-class women had been able to find success as essayists and novelists in the public since the eighteenth centuryindeed, George Eliot's screed against "Silly Lady Novelists" demonstrates that women wrote copiously, although their work was often considered hackneyed and was under-valued [28]. Queen Victoria herself supported education for women beyond drawing room skills [7]. Lovelace was the fortunate recipient of a top-notch education in all subjects, but especially 
mathematics and science. As the daughter of a Lord, and the eventual wife of a Count, Lovelace was able to refine her intellectual talents in ways that were just not accessible to the vast majority of the male and female population of England. ${ }^{3}$

At the same time, Lovelace's aristocratic position also imposed rigid expectations for her behavior as a Lady and Countess. Some have wondered why Lovelace herself did not write a separate article rather than merely translating Menabrea. Here, we see Lovelace's performance of gender causing her to defer to translation rather than original contribution. As she was expected to in many domains, Lovelace achieved her incisive insights by acting as the handmaiden to men's thoughts, in this case those of Babbage and Menabrea. Despite her mastery, the ideology of women's submission to men relegated her contributions to secondary status, perhaps even as dilettantism.

Although science has gained considerable cultural authority, specialization, and professionalism today, it is salutary to remember that during the nineteenth century, such authority was in the process of being made. Previously the domain of enthusiastic amateurs, science was becoming distinct from natural philosophy and natural history practiced by gentlemen scholars and clerical naturalists throughout the period [29]. The word scientist was not coined until 1833 [17]. When "science" was the domain of hobbyists, connections between what we now see as disparate disciplines and fields could be made readily, and such connections could produce startling discoveries. Lovelace's prediction regarding the possibilities for programming entailed weaving between mathematics, technology, and the symbolic realm of culture. In a century in which science was not yet seen as distinct from the arts and humanities, she could more easily blend these areas of knowledge without having to overcome disciplinary barriers. Lovelace's intellectual pursuits as an aristocrat were on par with the pastimes of many noble and gentle men and women similar to her rank, even if few were able to achieve original insight and invention to the degree that Babbage and Lovelace attained. Her special interest in mathematics and science was fairly unique for her sex at the time; yet, decades before her father had called her mother his "Princess of Parallelograms" [6].

\section{Conclusion: A Lesson Plan}

Ada Lovelace's position as a foremother in computing history thus offers several lessons to contemporary women in science and engineering. First, rather than being a woman working against or despite her context, Lovelace worked within it. This is not to say that her context did not hinder her achievements - it clearly did. Lovelace's program is relegated to footnotes of a translation, after all. But there were also ways in which Lovelace was only able to achieve what she did due to the time and circumstances in which she was born. Second, Lovelace's position in computing history is continually under attack as many accuse her of being a "token" in the history of computing. It seems clear that, while Lovelace did not write the very first program, she did write the first complex program and that this itself worth memorializing. Nor is her sex inconsequential. It is monumental that she is an early role model for women in science and engineering, as examples of women working within patriarchal paradigms are necessary to see what is possible. Third, and finally, Lovelace's achievement was a translation that wove between

\footnotetext{
${ }^{3}$ Babbage, although not aristocratic as Lovelace was, had a degree of wealth and access to privilege that enabled him to be educated and work in ways that were also inaccessible to most other men of the time.
} 
domains, just as her gender performance also obligated her to demur, defer, and translate the needs and wants of those around her, her translation also allowed her to unite ideas in ways that saw through to what computing could and would do for the world. She exemplifies the power of the Humanities and Sciences combined. Lovelace thus offers an interdisciplinary and intersectional example for women in engineering.

The above history should be integrated into curricula in science and engineering undergraduate classrooms in order to continue the change in origin narratives that Suw-Charman sought to pioneer with Ada Lovelace Day. To that end, we suggest the following lesson plan consisting of a one-hour video and 30 minute pre-discussion and 50 minute post-discussion to be used in undergraduate classrooms (such as Humanities and Technology courses or Introductory Computer Science courses) or outreach activities, such as Women in Science and Engineering events.

1. (30 minutes) Before watching the documentary, prompt students to write freely for 10 minutes about everything they know about Britain in the 1800s and the history of computer science.

a. Ask students to share highlights of what they thought about and then sketch some facts to augment or correct students' impressions about the century and/or the history of computer science. See BBC's British History timeline for resources on surveying this broad subject - the purpose here is to help students contextualize Ada Lovelace in time [34]. Do not spend more than 15 minutes orienting students regarding historical events as this subject could take up endless time.

2. (1 hour) Have students watch (as homework or during a dedicated session) the BBC's 2015 documentary, "Calculating Ada: The Countess of Computing" (59 minutes) [3536].

a. During the documentary, have students take notes on what they find strange / interesting / revealing about Ada Lovelace and her contributions to the history of computer science.

3. (50 minutes) During the next class session, or immediately after screening the documentary if there is time during an outreach activity, follow up with a discussion delving into the history of Ada Lovelace by using the following questions to scaffold responses. When necessary if discussion lags, ask students to either think-pair-share by sharing their ideas with a partner near them for 2-5 minutes before sharing with the larger class/group or ask students to write their thoughts freely for a 2-5 minutes and then share in conversation with the larger class/group.

a. How was Ada Lovelace able to contribute to what would become computer science in 1843 ? What challenges did she encounter? How did she deal with these challenges?

b. Does knowing about Ada Lovelace change your impressions of the history of computer science and women's roles in it?

c. Do you recognize any similarities between the struggles Ada had to confront in order to succeed and the struggles that women today might have to confront to succeed in computer science? What are the similarities and differences? Can Ada Lovelace's example help us imagine ways that we can lower barriers for women in science today? Why or why not? How so? 
The above activity is geared toward highlighting the knowledge that students already bring to the subject, introducing new ideas, and then reframing prior knowledge through those new ideas. Such a discussion will move in many different ways based on the many diverse experiences students bring to the subject, but the goal is for the example of Ada Lovelace to help students think intersectionally about the challenges of changing science and engineering culture to be more accommodating and welcoming of feminine perspectives. 


\section{References}

[1] K. Beddoes and M. Borrego, "Feminist Theory in Three Engineering Education Journals: 1995-2008," Journal of Engineering Education, vol. 100, no. 2, April 2011.

[2] P. Lockwood. “'Someone Like Me Can Be Successful': Do College Students Need SameGender Role Models?" Psychology of Women Quarterly, vol. 30, 2006.

[3] Computer History Museum, "Visit," https://computerhistory.org/visit/, (accessed June 20, 2020).

[4] Biography.com Editors, "Ada Lovelace," https://www.biography.com/scholar/ada-lovelace, April 2, 2014, updated July 29, 2020 (accessed August 20, 2020).

[5] C. Robson and C. T. Christ, eds. Norton Anthology of English Literature, Volume E:

Victorian Age. $9^{\text {th }}$ ed. Norton, 2012.

[6] W. Isaacson, The Innovators: How a Group of Hackers, Geniuses, and Geeks Created the

Digital Revolution. Simon and Schuster, 2014.

[7] B. Toole, “Ada Byron, Lady Lovelace.” http://www.cs.yale.edu/homes/tap/Files/ada-bio.html (Accessed June 8, 2020).

[8] B. Toole, Ada: The Enchantress of Numbers, Poetical Science. $2^{\text {nd }}$ Edition. Critical Connection, 2010.

[9] B. Wooley, The Bride of Science: Romance, Reason, and Byron's Daughter. Macmillan, 2015.

[10] D. Lundy. "Hon. Ada Augusta Byron". http://www.thepeerage.com/p2744.htm\#i27434, January 31, 2012, (viewed July 3, 2020).

[11] P. Cracroft-Brennan, "Lovelace, Earl of (UK, 1838)"

http://www.cracroftspeerage.co.uk/online/content/lovelace1838.htm, October 27, 2005 (accessed July 3, 2020).

[12] Anon., "New York Fifty Years Ago". Macon Georgia Telegraph. 9 April 1841.

https://newspaperarchive.com/entertainment-clipping-apr-09-1841-1422479/, October 2019, (accessed July 3, 2020).

[13] A. Hyman, Charles Babbage: Pioneer of the Computer. Princeton University Press, 1982.

[14] A. Sell, W. Mander, The Dictionary of Nineteenth-Century British Philosophers, Thoemmes Press, Bristol, 2002.

[15] Computer History Museum, "A Brief History,"

https://www.computerhistory.org/babbage/history/, (accessed August 20, 2020).

[16] Computer History Museum, "The Engines,"

https://www.computerhistory.org/babbage/engines/, (accessed August 20, 2020).

[17] M.R. Swaine, P. Freiberger, "Difference Engine", Encyclopedia Britannica, https://www.britannica.com/technology/Difference-Engine, (accessed May 20, 2020)

[18] D. Swade, The Cogwheel Brain: Charles Babbage and the Quest to Build the First Computer. Little, Brown, \& Co., 2000.

[19] P. Ceruzzi, Computing: A Concise History, United States Smithsonian Institution, 2012.

[20] B. Gross, "The French Connection". Distillations Magazine,

https://www.sciencehistory.org/distillations/magazine/the-french-connection, 1 (3): 10-13, (Fall

2015), (accessed May 20, 2020).

[21] J. Essinger. Jacquard's Web: How a Hand-Loom Led to the Birth of the Information Age. Oxford University Press, 2007.

[22] Wikipedia, "Jacquard Machine," https://en.wikipedia.org/wiki/Jacquard_machine, (accessed 
June 20, 2020).

[23] E. Hobsbawm, The Age of Revolution 1789-1848, Random House, 2008.

[24] W. Newton, The London Journal of Arts and Sciences; A Record of the Progress and

Invention as Applied to the Arts, Vol 23, Sec 24, p. 334, June1866 (accessed July 2020).

[25] A. Lovelace, "Notes on Translation." Bibliothèque Universelle de Genève, October, 1842,

No. 82. https://www.fourmilab.ch/babbage/sketch.html (accessed 5 September

2019).

[26] S. Target, Sinclair. "What Did Ada Lovelace's Program Do?" Two Bit History.

https://twobithistory.org/2018/08/18/ada-lovelace-note-g.html, August 18, 2018, (accessed June

$8,2020)$.

[27] S. Charman-Andereson. "History of Ada Lovelace Day." FindingAda.com

https://findingada.com/about/history-of-ada-lovelace-day/, (accessed February 8, 2021).

[28] G. Eliot. "Silly Novels by Lady Novelists." Westminster Review, October 1856.

[25-29] J. Van Whye, "Victorian Science: An Introduction."

http://victorianweb.org/science/intro.html, December 6, 2008, (accessed June 9, 2020)

[30] D. Roegel, "Prototype Fragments from Babbage's First Difference Engine," IEEE Annals of the History of Computing, vol. 31, April-June 2009.

[31] D. Swade, A. Bromley, R. Crick, M. Wright, P. Turvey, "The Babbage Engine" Computer

History Museum, https://www.computerhistory.org/babbage/, (accessed May 20, 2020).

[32] M. Shiels, "Victorian 'supercomputer' is reborn," BBC News,

http://news.bbc.co.uk/2/hi/technology/7391593.stm, May 10, 2008, (accessed May 20, 2020).

[33] M. Guinness, " $19^{\text {th }}$ century mechanical computer project set to begin."

https://www.dw.com/en/19th-century-mechanical-computer-project-set-to-begin/a-6703016,

January 23, 2012, (accessed June 25, 2020).

[34] BBC, "History: Victorians," https://www.bbc.co.uk/history/british/victorians/, (accessed April 9, 2021).

[35] BBC, "Calculating Ada: The Countess of Computing,"

https://www.bbc.co.uk/programmes/p030s5bx, (accessed April 9, 2021).

[36] Forgottendiaries, "BBC DOCUMENTARY: Calculating Ada - The Countess of

Computing 2015," https://youtu.be/QgUVrzkQgds (accessed April 9, 2021) 